\title{
Regional GPS receiver networks for monitoring local mid-latitude total electron content
}

\author{
Angela Vernon and Ljiljana R. Cander \\ Rutherford Appleton Laboratory, Chilton, Didcot, Oxon, U.K.
}

\begin{abstract}
Two regional GPS receiver networks from the Ordnance Survey U.K. (OS) and the Italian Space Agency (ASI) have been used for monitoring mid-latitude Total Electron Content (TEC) during quiet and disturbed ionospheric conditions in the current solar cycle. A few quiet and disturbed days in March and April 2002 were examined. These showed how the temporal and spatial patterns of changes develop and how they are related to solar and geomagnetic activity for parameter descriptive of plasmaspheric-ionospheric ionisation. Use is then made of computer contouring techniques to produce snapshots of daily maps of TEC for these different regional areas.
\end{abstract}

Key words regional ionospheric modelling ionospheric variability - ionospheric storm - Total Electron Content (TEC)

\section{Introduction}

It is well known that the ionosphere, as a major region of the Earth's environment, shows great temporal and spatial variations. Temporal variations include cyclical effects with diurnal, seasonal and solar cycle periods. Spatial variations deal with geographical and also significant variations in ionospheric behaviour in different ionospheric layers. In studying these variations, particularly important are ionospheric disturbances with their damaging effects on radio communications systems that involve links between earth and space at frequencies up to at least $4 \mathrm{GHz}$ (Bishop et al., 1996). The deter-

Mailing address: Angela Vernon, Rutherford Appleton Laboratory, Radio Communications Research Unit, Chilton, Didcot, Oxon OX11 0QX, U.K.; e-mail: angela.vernon@rl.ac.uk mination of whether the ionospheric conditions will generate significant system degradation involves a continuous monitoring and extensive study of ionospheric variability at local, regional and global levels. In this paper the emphasise is on the regional ionospheric variability as seen from OS and ASI GPS receiver networks in fig. la,b during the solar-terrestrial conditions given in table I.

Most of the studies so far indicate that in order to realistically specify the global undisturbed ionosphere, hourly ionospheric observation every $30^{\circ}$ of longitude and $15^{\circ}$ of latitude are needed. Such a minimum world-wide grid network would provide at least $20 \%$ improvement in the specification of the ionosphere over the median condition (Rush, 1972). However, during geomagnetic disturbances, the observations should be more frequent both in time and space (Bradley and Cander, 2002). Such a network of observing GPS sites is currently in existence (e.g., OS and ASI) giving the potential improvement to propagation forecasting. The scale size of the changes in the structure and ionisation content are quite variable and are investigated here on regional basis. 


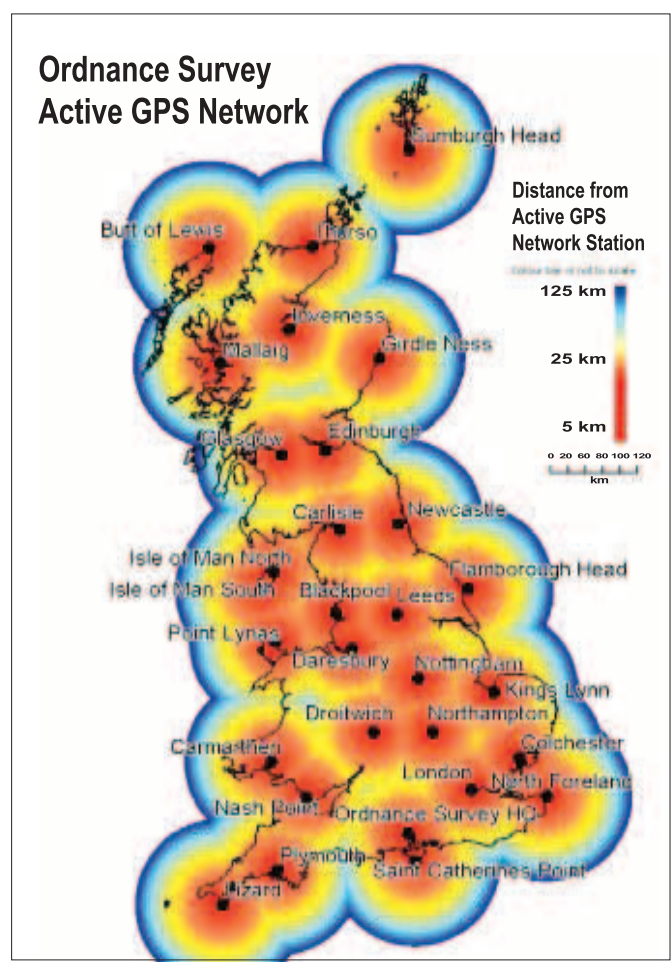

(a)

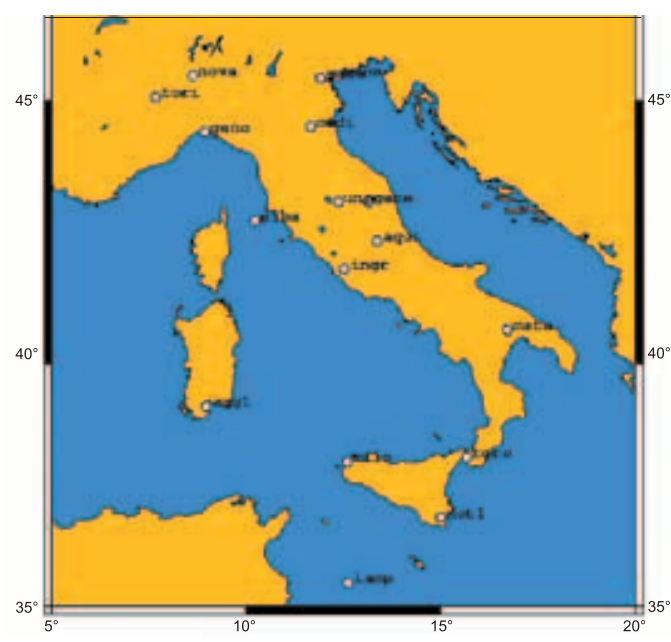

(b)

Fig. 1a,b. Maps of the OS (a) and the ASI (b) GPS sites considered in this paper as two regional areas.
The vertical TEC estimations along all GPS satellite links in view for elevation angles greater than $10^{\circ}$ are derived using a technique developed by Ciraolo $(1993,2000)$ and recently discussed by Cander and Ciraolo (2002). The residual RMS values of the observations result generally in the order of approximately 2 TEC units (1 TEC unit $=10^{16} \mathrm{el} / \mathrm{m}^{2}$ ).

\section{Spatial and temporal regional TEC structure}

The possible origins of plasmasphericionospheric variability can be the solar ionising flux, the interaction of the solar wind with the Earth's magnetic field and even meteorological influences (Prölss, 1995). Typical multi-point observational TEC results for ASI sites are given in figs. 2a-c. They show clearly geomagnetic activity effects at the regional plasmasphericionospheric conditions. Evidently there is a part of scatter in figs. $2 \mathrm{a}-\mathrm{c}$ that can be only attributed to the higher level of geomagnetic activity on both 5 and 6 March than on 8 March 2002, displaying pronounced upper atmospheric sensitivity to the rapidly changing solar-terrestrial activity as given in table I. In particular, ionospheric vertical TEC variations are found to have relatively small magnitude (12 TECU during daytime and 8 TECU during night-time) for quiet conditions on 8 March 2002. Thus, it is unlikely that short-term solar EUV changes can produce the observed spatial TEC variability. Figures $2 \mathrm{a}-\mathrm{c}$ show that there is a marked TEC variation from hour to hour as well as within $1 \mathrm{~h}$ related to the receiver's locations in a rather complicated way that cannot generally be linked directly to any single solar terrestrial event. If the difference is of order of 30 TECU during daytime and 20 TECU during night-time between one location and another in the area of $15^{\circ}$ longitude and $10^{\circ}$ latitude on 5 and 6 March 2002, it is expected that the behaviour of the plasmasphere-ionospheres structure during major geomagnetic disturbances departs even more significantly from that described in figs. 2a-c. Although daytime variability in TEC is found to be considerably larger than night-time, fig. 3a,b shows important difference between two regional areas TEC during nights hours on 4 March 2002. 
Regional GPS receiver networks for monitoring local mid-latitude total electron content

Table I. Solar-terrestrial conditions in March and April 2002 (SIDC (RWC-Belgium) http://sidc.oma.be)).

\begin{tabular}{ccccccc}
\hline \hline Date & RC & $10 \mathrm{~cm}$ & Ak & BKG & M & X \\
\hline 2002 Mar 03 & 178 & 183 & 012 & B9.8 & 0 & 0 \\
2002 Mar 04 & - & 175 & 011 & B7.3 & 0 & 0 \\
2002 Mar 05 & - & 172 & 024 & B6.4 & 0 & 0 \\
2002 Mar 06 & 165 & 178 & 017 & B9.9 & 0 & 0 \\
2002 Mar 07 & - & 180 & 008 & B7.2 & 0 & 0 \\
2002 Mar 08 & - & 177 & 004 & C1.0 & 0 & 0 \\
2002 Mar 29 & - & 181 & 007 & B7.7 & 0 & 0 \\
2002 Mar 30 & 145 & 189 & 018 & C1.8 & 2 & 0 \\
2002 Mar 31 & 179 & 204 & 024 & C1.4 & 1 & 0 \\
2002 Apr 01 & 165 & 207 & 018 & C1.0 & 0 & 0 \\
2002 Apr 02 & 220 & 206 & 012 & C1.4 & 0 & 0 \\
2002 Apr 03 & - & 209 & 015 & B8.1 & 0 & 0 \\
2002 Apr 04 & 248 & 216 & 006 & C1.0 & 2 & 0 \\
2002 Apr 05 & 213 & 217 & 004 & C1.3 & 0 & 0 \\
2002 Apr 06 & 249 & 206 & 004 & C1.1 & 0 & 0 \\
2002 Apr 07 & 211 & 208 & 010 & C1.5 & 0 & 0 \\
\hline
\end{tabular}

$\mathrm{RC}=$ sunspot index from Catania Observatory (Italy); $10 \mathrm{~cm}=10.7 \mathrm{~cm}$ radioflux (DRAO, Canada); Ak = Ak index Wingst (Germany); BKG = Background GOES X-ray level (NOAA, U.S.A.); M, X = number of X-ray flares in $\mathrm{M}$ and X class, see below (NOAA, U.S.A.)

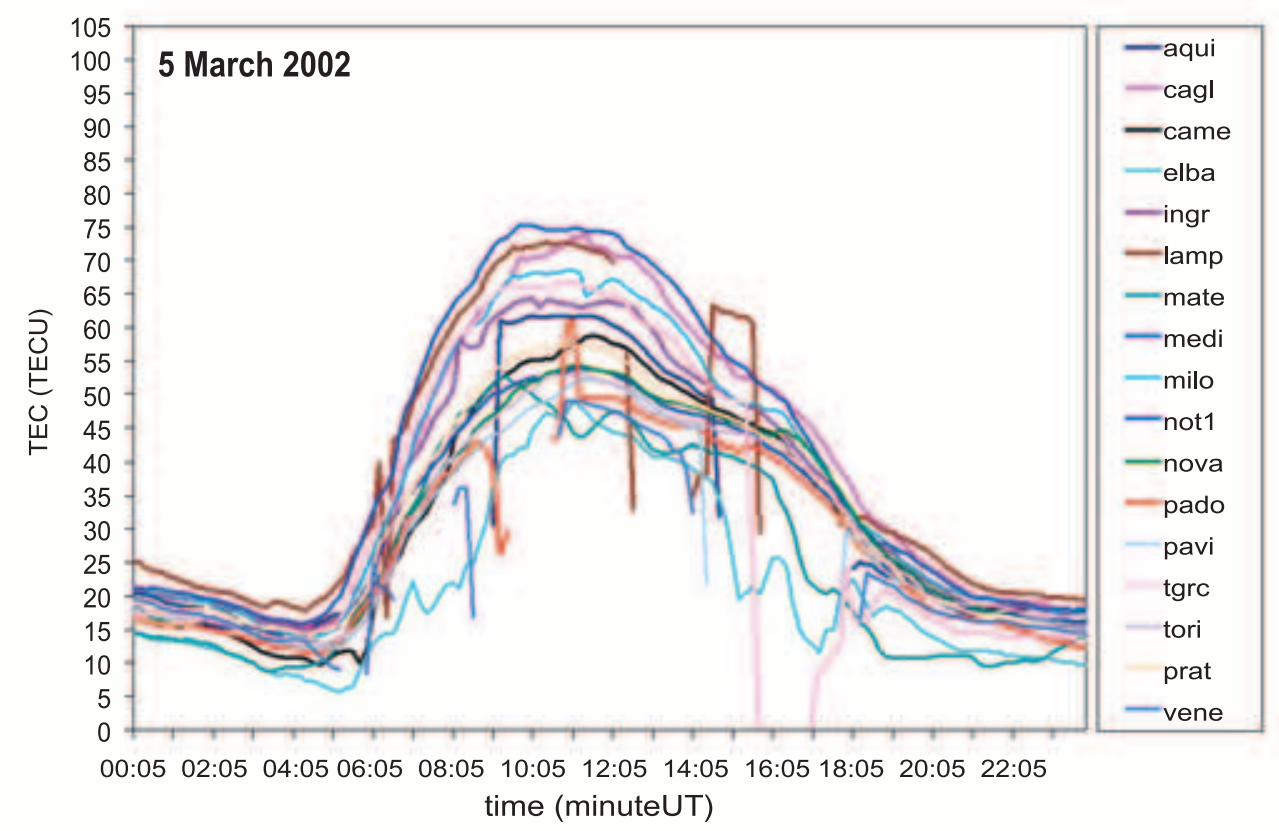

Fig. 2a. Daily vertical TEC at ASI during disturbed 5 March 2002 day. 


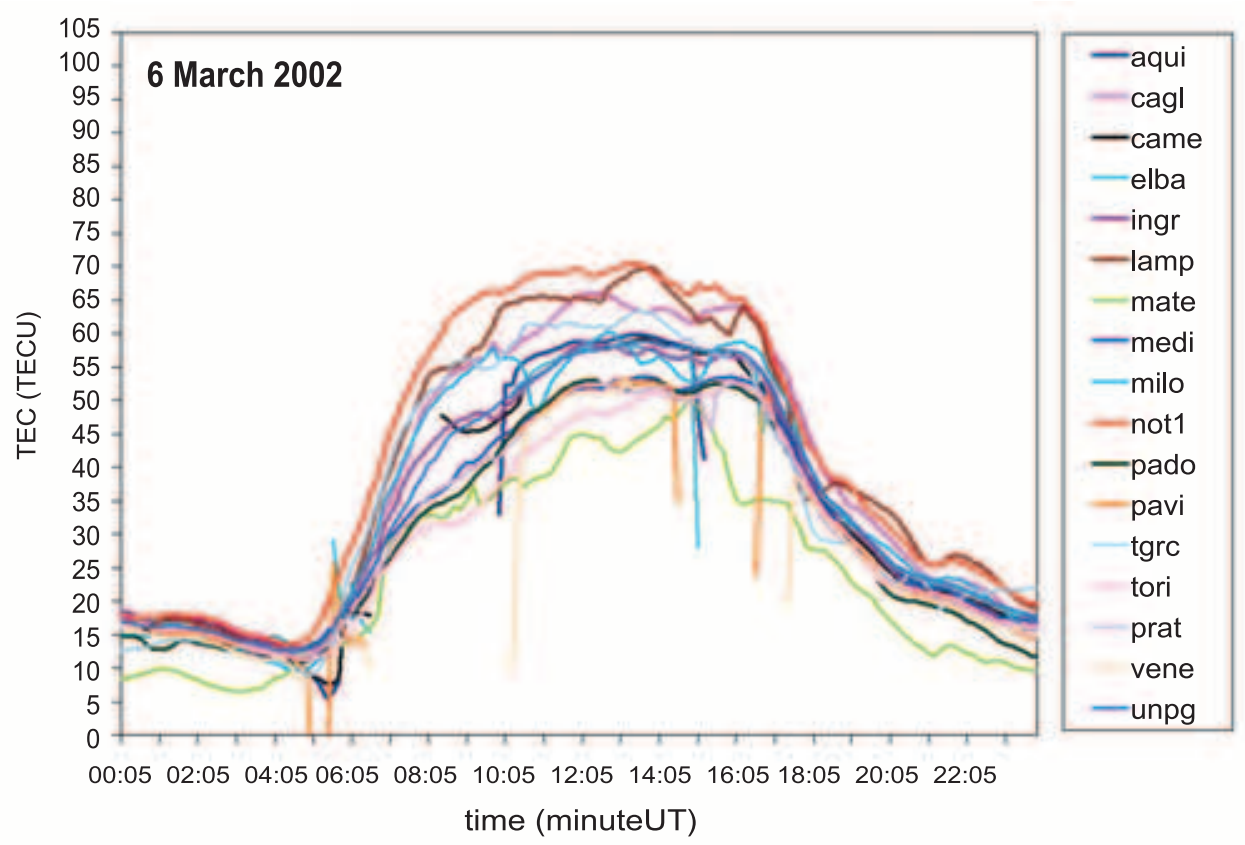

Fig. 2b. Daily vertical TEC at ASI during disturbed 6 March 2002 day.

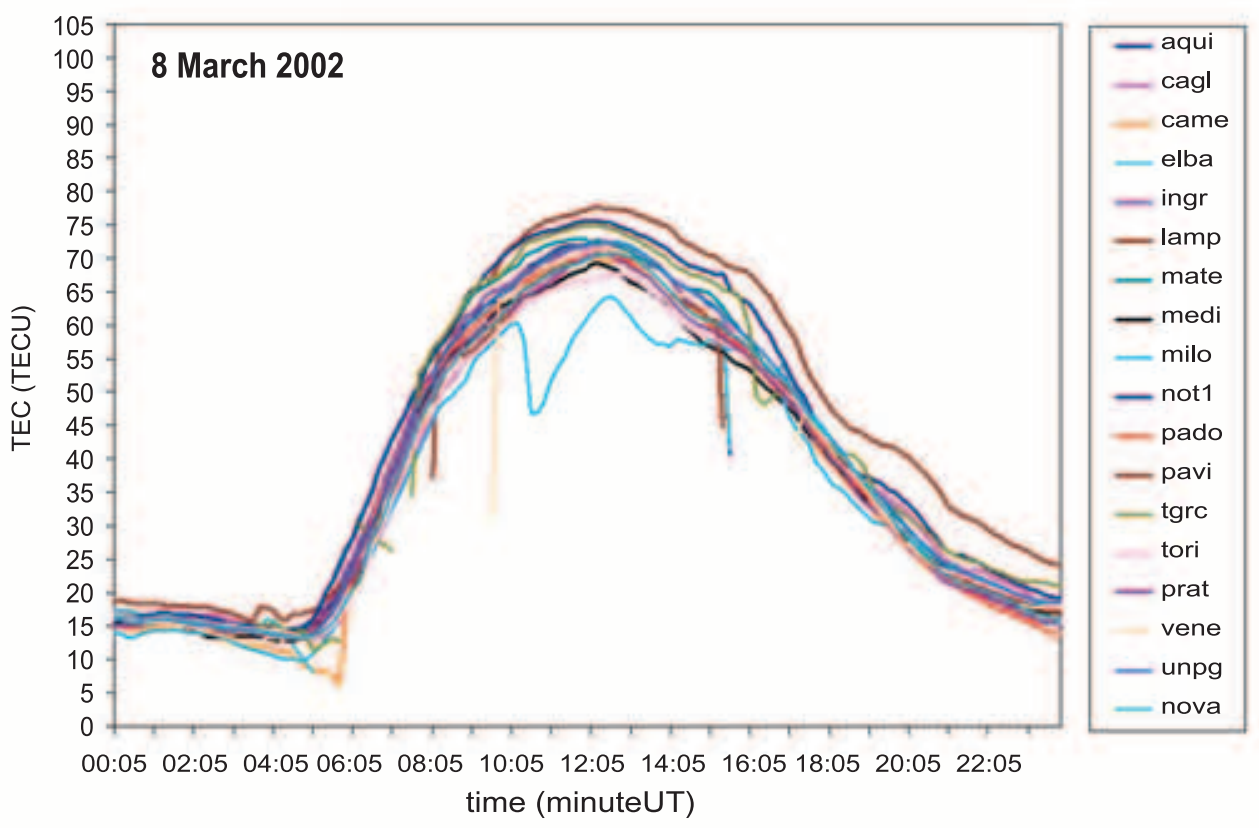

Fig. 2c. Daily vertical TEC at ASI during quiet 8 March 2002 day. 

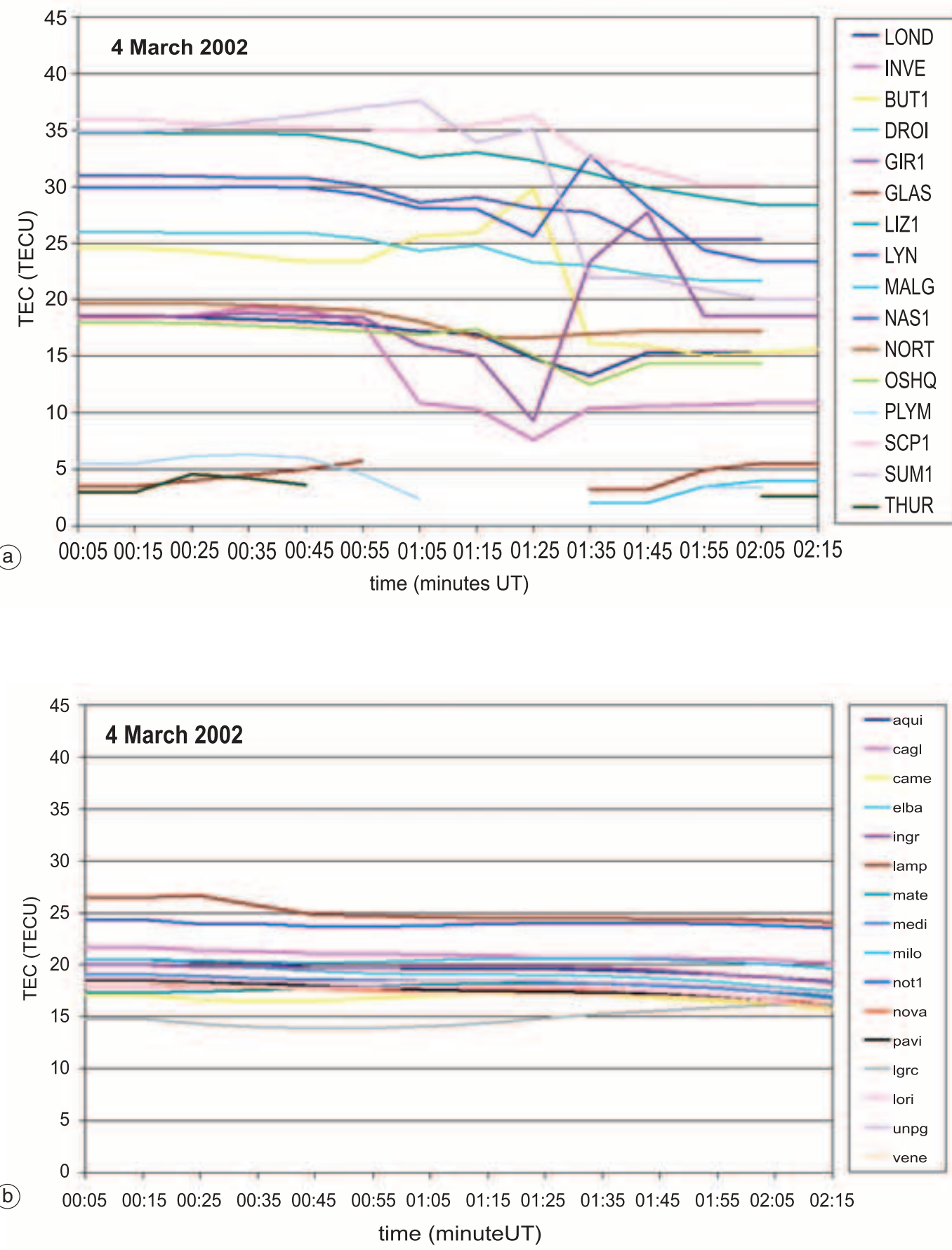

Fig. 3a,b. Night-time vertical TEC from OS (a) and ASI (b) on 4 March 2002. 

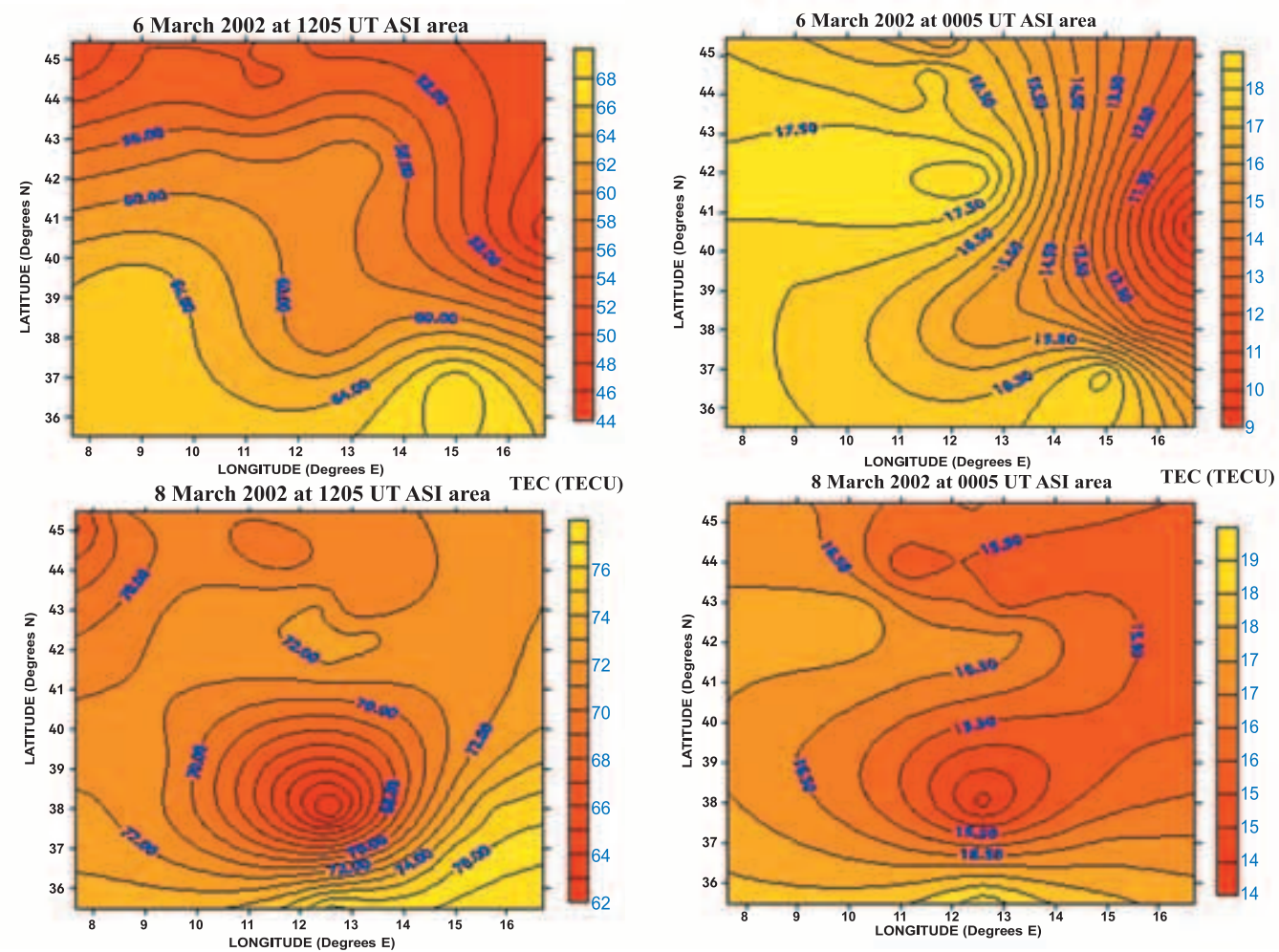

(a)

(b)

Fig. 4a,b. Maps showing the ionospheric vertical TEC over the ASI for 6 and 8 March 2002 generated by Kriging. Contours are labelled in units of TEC with fit of data from 1205 (a) and 0005 (b) UT.

The possibility of using the Kriging contouring technique, which behaves nonlinearly with respect to the spatial co-ordinates (Samardjiev et al., 1993; Stanisławska et al., 1996; Cander and Vernon, 2000; Stanisławska et al., 2002), for TEC mapping over a limited geographical area in Europe is further explored in this paper. Grid values are generated at 10 min intervals to show the spatial extent of ionospheric TEC changes over the OS and ASI areas. The Kriging contouring of the GPS vertical TEC data from all stations shown in fig. 1a,b was performed for selected days in March and April 2002. Results are presented only for 0005,1205 UT over the ASI area and 0805, 1405 UT over OS area in figs. $4 \mathrm{a}, \mathrm{b}$ and $5 \mathrm{a}, \mathrm{b}$, respectively. They reveal that the maps differ significantly by several TEC units, which is expected from the structures in TEC variations clearly seen at figs. $2 a-c$ and $3 a, b$. This emphasises a unique opportunity to monitor the ionosphere regularly by numerous GPS ground sites on the regional basis.

Accordingly, there is a considerable spatial/ temporal structure over limited ASI and OS areas that can be seen on the maps in figs. $4 \mathrm{a}, \mathrm{b}$ and $5 \mathrm{a}, \mathrm{b}$, respectively. The 5 and 31 March minor storms affected the plasmasphere-ionosphere over these two areas in such a way that the TEC variation appeared as a negative-value phase. More importantly the common pattern consists of significant TEC variability at limited geographical areas. Thus, it is obvious that such a 

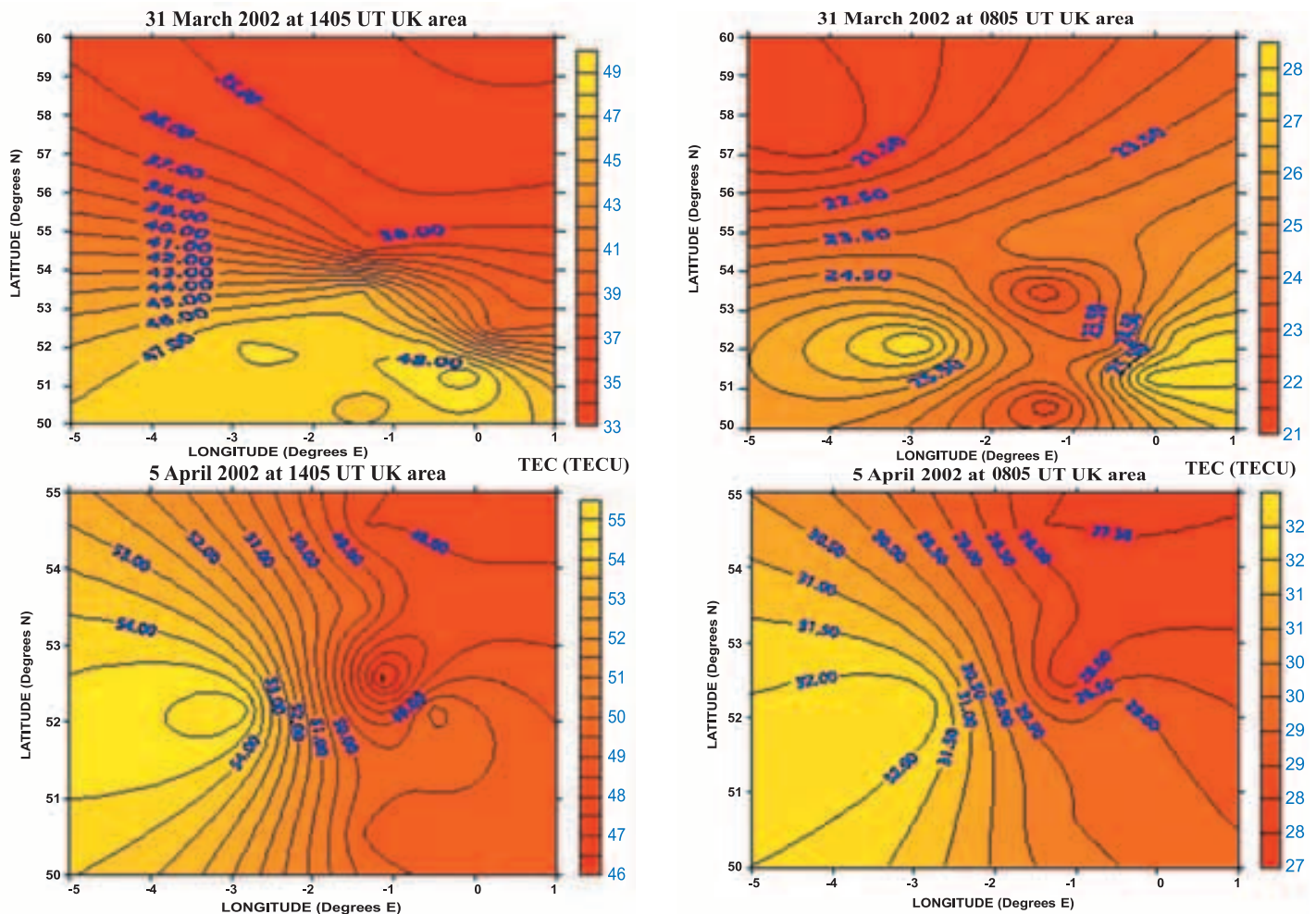

(a)

(b)

Fig. 5a,b. Maps showing the ionospheric vertical TEC over the OS for 31 March and 5 April 2002 generated by Kriging. Contours are labelled in units of TEC with fit of data from 1405 (a) and 0805 (b) UT.

spatial/temporal structure in the ionospheric and plasmaspheric ionisation during minor geomagnetic storms creates the great difficulty in matching the rapid TEC variations in forecasting models and data as storms develop. The physical mechanisms that lead to such a complex behaviour even at this limited area neither can be explained nor forecast easily with current knowledge (Fuller-Rowell, 1998).

\section{Discussion and conclusions}

Advantage of the limited area TEC observations with the regional GPS networks is not only its wide coverage of space but its high spatial and temporal resolution, and wide temporal coverage. It helps in further understanding the relationships between the regional plasmaspheric-ionospheric structure and associated solar-terrestrial events. This should lead to a regional storm forecasting technique based on continuous and rapid measurements over limited areas as these at the ASI and OS. It is also important for determining the required geographical spacing of TEC monitoring locations for different practical applications.

The present study has been an area-centred one in which specific examples of regional TEC variability were investigated. Although ionospheric storms are global phenomena, the findings here emphasise the means for monitoring 
and possibly forecasting storms and perturbations of the ionosphere over different spatial and temporal scales. The aim of any trans-ionospheric propagation-modelling project is to study the variability of the various physical parameters, such as the ionospheric critical frequency $f_{0} F_{2}$ and TEC and relate them to solar-terrestrial events. Therefore, the database of high time resolution TEC GPS receiver networks can be used for developing regional plasmaspheric-ionospheric model as a part of global ionospheric and space weather models. Coupled with global real-time monitoring and warning systems, such a model will be able to identify the onset and location of the ionospheric storm conditions and forecast the immediate future.

\section{Acknowledgements}

The Radiocommunications Agency of the DTI has funded this work. The authors would like to express appreciation to the Italian Space Agency and the Ordnance Survey U.K. for providing RINEX data as well as to Dr L. Ciraolo for using his 'TECmake' software for TEC evaluation.

\section{REFERENCES}

Bishop, G.J., A.J. Mazzella, E.A. Holland and S. RaO (1996): An overview of ionospheric effects and mitigation in RF communication, navigation and surveillance, in Proceedings of the Ionospheric Effects Symposium, Alexandria, U.S.A., 11-21.

Bradley, P.A. and Lj.R. CANDER (2002): Proposed terminology for the classification and parameters for the quantification of variability in ionosphere morphology, Ann. Geophysics, 45 (1), 97-103.

CANDER, Lj.R. and A. VERNON (2000): TEC mapping over Europe by kriging contouring technique, paper presented at Millennium Conference on Antennas and Propagation, April, Davos, Switzerland, CD-ROM p1172.pdf.

CANDER, Lj.R. and L. CiRAOLO (2002): First step towards specification of plasmaspheric-ionospheric conditions over Europe on-line, Acta Geod. Geophys. Hung., 37 (2-3), 153-161.

CIRAOLO, L. (1993): Evaluation of GPS L2-L1 biases and related daily TEC profiles, in Proceedings of the GPS/ Ionosphere Workshop, Neustrelitz, Germany, 90-97.

CiRAOlO, L. (2000): Results and problems in GPS TEC evaluation, in Proceedings of the Radio Communications Research Units, 1st GPS TEC Workshop, Chilton, U.K., 47-60.

Fuller-Rowell, T.J., M.V. Codrescu, R.J. MofFetT and S. QUEGAN (1998): Response of thermosphere and ionosphere to geomagnetic storms, J. Geophys. Res., 99, 3893-3914.

PRÖLSS, G.W. (1995): Ionospheric F-region storms, in Handbook of Atmospheric Electrodynamics, edited by H. Volland (CRC Press/Boca Raton), vol. 2, 195-248.

RUSH, C. (1972): Improvements in ionospheric forecasting capability, AFCRL-72-0138, Environmental Research Papers, n. 387, Air Force Cambridge Research Laboratory, Bedford, Massachusetts, U.S.A.

SAMARDJIEV, T., P.A. BRADLEY, Lj.R. CANDER and M.I. DiCK (1993): Ionospheric mapping by computer contouring techniques, Electron. Lett., 29 (20), 1794-1975.

STANISŁAWSKA, I., G. JUCHNIKOWSKI and Lj.R. CANDER (1996): Kriging method of ionospheric parameter $f_{0} F_{2}$ instantaneous mapping, Ann. Geofis., 39 (4), 845-852.

STANISŁAWSKA, I., G. JUCHNIKOWSKI, Lj.R. CANDER, L. Ciraolo, P.A. Bradley and A. SWiateK (2002): Kriging method of TEC instantaneous mapping, $A d v$. Space Res., 29 (6), 1017-1020.

(received May 6, 2002; accepted October 4, 2002) 